\section{Predicting high blood alcohol levels for animals in a group situation}

\section{MARTIN W. SCOTT and MARK E. WILSON} Eastern Washington State College, Cheney, Washington 99004

A system has been developed that can reliably predict when an animal, living in a group situation with free access to an ethanol solution, will have a high blood alcohol level (BAL). The need for this system, coined PROBAL (PRedicting Optimal Blood Alcohol Levels), was dictated by the following research question: What variables arising from a social situation contribute to the development and maintenance of addictive drinking patterns in pig-tailed macaques (Macaca nemestrina) having free access to an ethanol solution?

Previous investigations with nonhuman primates have typically used isolated animals consuming alcohol by intubation (Ellis \& Pick, 1971), self-administration via an indwelling catheter (Woods, Ikomi, \& Winger, 1971), as the only available liquid (Mello \& Mendelson, 1971,

This program was developed for research supported in part by National Institute of Health Grant RR00166 to the Regional Primate Research Center at the University of Washington, a grant from the Alcoholism and Drug Abuse Institute at the University of Washington, and a grant from the Primate Research Program at Eastern Washington State College.
1973), or in a liquid diet (Pieper, Skeen, McClure, \& Bourne, 1972). The time at which blood was drawn for determination of BALs was a matter of convenience: either daily or weekly or, as in the case of intubation, after $\mathbf{n}$ number of hours had elapsed since administration. Animals in a group situation with free access to alcohol tend to drink in binges (Elton, Greaves, Bunger, \& Pyle, Note 1). Consequently, a system was needed that would reliably predict when a particular animal would have a high BAL.

In order to meet this need, PROBAL, representing a series of five discrete subprograms, was developed. Written in FORTRAN II, it was designed to run on a PDP-8/F computer (Digital Equipment Corporation) having $8 \mathrm{~K}$ memory, with input-output via a terminal and data storage on DECtapes (magnetic tapes from Digital Equipment Corporation).

The data acquisition system, described elsewhere (Elton \& Kjeldsen, 1976), records the total amount of ethanol consumed each day for each animal. A sub. program allows this data to be input and converts the information to grams of ethanol consumed per kilogram body weight per hour per day for each animal. This information is then stored on tape as daily files for each animal; another subprogram can be run to store these as weekly files if desired. If stored as weekly files, the daily information can be accessed when needed.

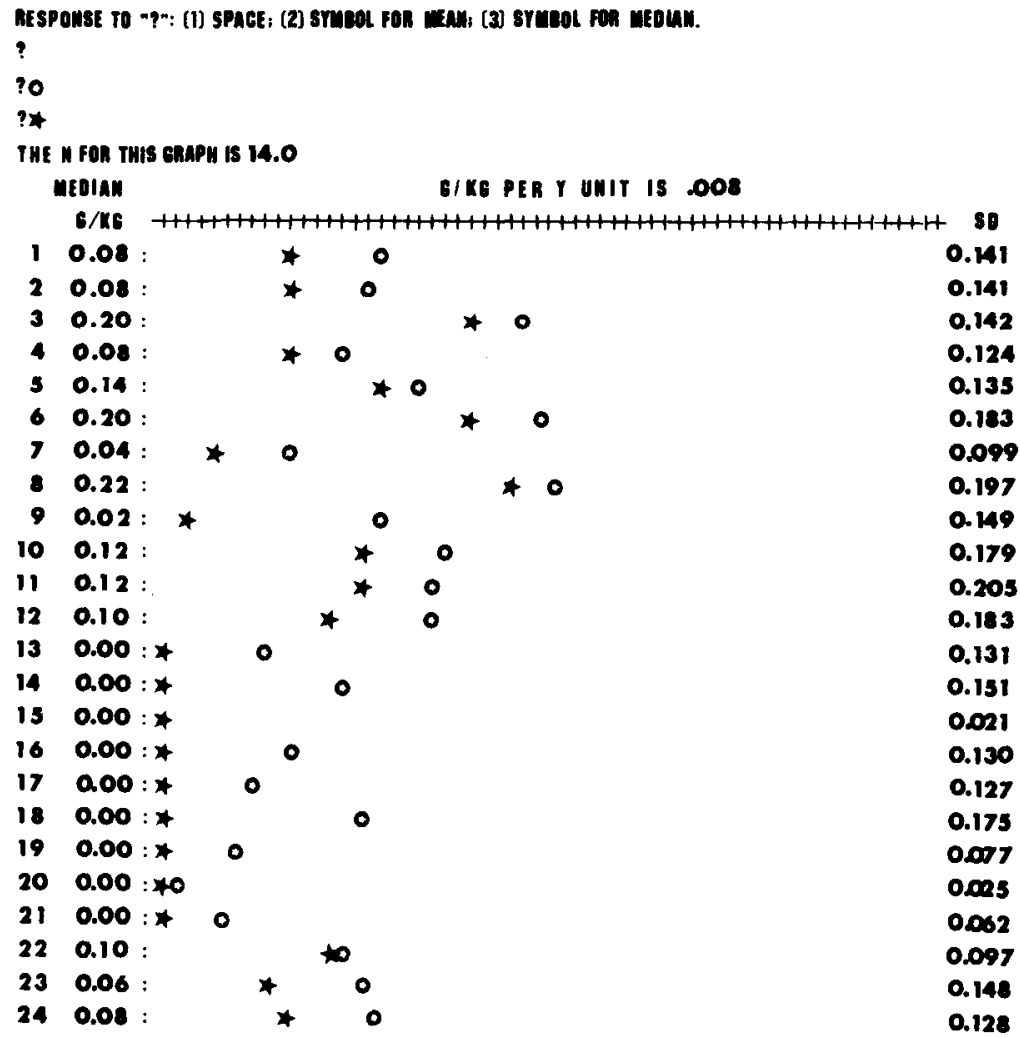

Figure 1. PROBAL output for the combination of 14 daily files for a particular animal. Mean values are indicated by a circle and median values are indicated by a star. When the mean and median values are the same for a given hour, only the symbol for the median is shown. 
Once the data is stored on tape, a subprogram can plot the individual daily drinking pattem as grams of ethanol consumed per kilogram body weight as a function of time for a particular monkey on a chosen day. Another subprogram can be run that combines up to 30 daily files for a particular monkey. For each hour, the output lists the median grams per kilogram ethanol consumed, plots the mean and median grams per kilogram ethanol consumed, and lists the standard deviation. Figure 1 is an example of this output. The variability in the drinking patterns can be seen in the differences between the mean and median values for each hour. This information, together with the standard deviation, allows a decision to be made concerning ethanol consumption. From this, one can predict when an animal may have a high BAL. For example, the information provided in Figure 1 allowed the experimenter to predict that the animal would have a high BAL at Hour 6. A subsequent blood draw at Hour 6 revealed a BAL of $.105 \%$.

This same subprogram allows the combination of daily files, so that drinking patterns can be compared between males and females, dominant and submissive animals, high and low drinkers, or other combinations.

Availability. A complete listing of PROBAL can be obtained from the authors at no cost. Requests should be mailed to Mark E. Wilson, Department of Psychology, Emory University, Atlanta, Georgia 30322.

\section{REFERENCE NOTE}

1. Elton, R. H., Greaves, D. A., Bunger, D. R., \& Pyle, T. W. Patterns of ethanol ingestion by a group of pig-tailed macaques (Macaca nemestrina). Unpublished manuscript.

\section{REFERENCES}

Ellis, F. W., \& Pick, J. R. Ethanol intoxication and dependence in rhesus monkeys. In N. K. Mello \& J. H. Mendelson (Eds.), Recent advances in studies on alcoholism. Washington, D. C: U. S. Government Printing Office, 1971.

Elton, R. H., \& KJeldsen, T. Monitoring response patterns of individual monkeys living in groups. Behavior Research Methods \& Instrumentation, 1976, 8, 481.

Mello, N. K., \& Mendelson, J. H. The effects of drinking to avoid shock on ethanol intake in primates. In M. K. Roach, W. M. Mclsaac, \& P. J. Creaven (Eds.), Biological aspects of alcohol. Austin: The University of Texas Press, 1971.

Mello, N. K., \& Mendelson, J. H. Studies of the development of alcohol addiction in infant monkeys. Annals of the New York Academy of Sciences, 1973, 215, 145-161.

Pieper, W. A., Skeen, M. J., McClure, H. M., \& BoURNE. P. G. The chimpanzee as an animal model for investigating alcoholism. Science, 1972, 176, 71-73.

Woods, J. H., Іком. F., \& Winger, G. The reinforcing property of ethanol. In M. K. Roach, W. M. McIsaac, \& P. J. Creaven (Eds.), Biological aspects of alcohol. Austin: The University of Texas Press, 1971. 